\title{
Электронный квантовый транспорт в псевдоморфных и метаморфных квантовых ямах на основе $\ln _{0.2} \mathrm{Ga}_{0.8} \mathrm{As}$
}

\author{
() А.Н. Виниченко, Д.А. Сафонов " Н.И. Каргин, И.С. Васильевский \\ Национальный исследовательский ядерный университет „МИФИ“, \\ 115409 Москва, Россия \\ ฯ E-mail: safonov.dan@mail.ru
}

(Получена 15 октября 2018 г. Принята к печати 22 октября 2018 г.)

\begin{abstract}
Впервые реализованы и исследованы метаморфные глубокие квантовые ямы МНЕМТ $\mathrm{In}_{0.2} \mathrm{Ga}_{0.8} \mathrm{As} / \mathrm{In}_{0.2} \mathrm{Al}_{0.8} \mathrm{As}$ (глубина 0.7 эВ для Г-электронов) с различной конструкцией метаморфного буфера. Проведен сравнительный анализ электронных свойств метаморфной МНЕМТ- и псевдоморфной РНЕМТ-структур при одинаковом легировании. Обнаружено увеличение подвижности и концентрации электронов в интервале температур 4-300 K в МНЕМТ-структуре с линейным метаморфным буфером по сравнению с РНЕМТ-структурой, что связано с увеличением глубины квантовой ямы. Из низкотемпературного магнетотранспорта обнаружено, что в МНЕМТ-структуре существенно снижается квантовое время релаксации импульса за счет усиления механизмов рассеяния на малые углы на структурных дефектах и неоднородностях, при этом доминирующим в структурах обоих типов является рассеяние на удаленной ионизованной примеси.
\end{abstract}

DOI: 10.21883/FTP.2019.03.47288.9001

\section{1. Введение}

Гетероструктуры PHEMT (pseudomorphic high-electron-mobility transistor) на основе $\mathrm{A}^{\mathrm{III}} \mathrm{B}^{\mathrm{V}} \mathrm{c}$ мышьяком, выращенные на подложках $\mathrm{GaAs}$, в наше время являются одними из основных типов структур, используемых в промышленной сверхвысокочастотной (СВЧ) полупроводниковой электронике. На их основе создаются как дискретные транзисторы, так и сложные интегральные схемы $X$ - и $K$-диапазона длин волн [1-3].

Глубина квантовой ямы (КЯ) является одной из фундаментальных характеристик НЕМТ-структур, в РНЕМТ $\mathrm{Al}_{x} \mathrm{Ga}_{1-x} \mathrm{As} / \mathrm{In}_{y} \mathrm{Ga}_{1-y} \mathrm{As} / \mathrm{GaAs}$ определяется мольными долями в тройных твердых растворах AlAs $(x)$ и InAs $(y)$ и увеличивается с возрастанием $x, y$. В КЯ с высокой электронной плотностью, предназначенных для транзисторных применений, обычно ограничения выбора долей $x$ и $y$ обусловлены тем, что при $x>25 \%$ в легированном донорами кремния слое $\mathrm{Al}_{x} \mathrm{Ga}_{1-x} \mathrm{As}$ часть электронов захватывается на $D X$-центры (ловушки) [4,5], а высокие значения $y(y>25-30 \%)$ ограничены переходом к неупругой релаксации псевдоморфно-напряженного слоя $\mathrm{In}_{y} \mathrm{Ga}_{1-y} \mathrm{As}$ [6]. Литературные данные по положению $D X$-центров в InAlAs различаются [7-9], однако из-за большего разрыва зон в $\operatorname{In}_{x} \mathrm{Al}_{1-x} \mathrm{As} / \mathrm{In}_{x} \mathrm{Ga}_{1-x} \mathrm{As}$ по сравнению c $\operatorname{In}_{x} \mathrm{Al}_{1-x} \mathrm{As} / \mathrm{Al}_{x} \mathrm{Ga}_{1-x} \mathrm{As}$ влияние $D X$-центров на ионизацию должно быть меньше в структуре $\operatorname{In}_{x} \mathrm{Al}_{1-x} \mathrm{As} / \mathrm{In}_{x} \mathrm{Ga}_{1-x} \mathrm{As}$.

Механическое напряжение дополнительно приводит к увеличению энергии запрещенной зоны в слое $\mathrm{In}_{y} \mathrm{Ga}_{1-y}$ As на $\sim 0.07$ эB $[10,11]$, а значит, к уменьшению глубины КЯ. Ограничение глубины КЯ РНЕМТ-структуры на уровне $\sim 0.35$ эВ приводит к тому, что при сильном легировании возникает дипольное электрическое поле в области спейсера. Увеличение туннельной проницаемости барьера КЯ приводит к возрастанию амплитуды волновых функций электронов в области барьера и увеличению рассеяния электронов на ионизованных донорах [12].

Подавить данный негативный эффект возможно за счет усиления локализации электронов в более глубокой квантовой яме при сохранении высокой электронной плотности. Увеличение глубины КЯ за счет увеличения содержания InAs в канале $\operatorname{In}_{y} \mathrm{Ga}_{1-y}$ As также невозможно выше определенных значений (обычно 25\% InAs), так как слой $\operatorname{In}_{y} \mathrm{Ga}_{1-y}$ As имеет механическую деформацию, и при превышении критической толщины слоя электронные транспортные характеристики резко ухудшаются из-за неупругой релаксации канала с образованием дислокаций несоответствия. B InAlGaAs-гетеросистеме наибольший разрыв Г-долины зоны проводимости при сохранении изоморфного состава барьерного и узкозонного слоев достигается в гетеропереходе $\mathrm{In}_{x} \mathrm{Al}_{1-x} \mathrm{As} / \mathrm{In}_{x} \mathrm{Ga}_{1-x} \mathrm{As}$ при относительно небольшом содержании In. При $x<0.37 \operatorname{In}_{x} \mathrm{Al}_{1-x}$ As является непрямозонным, что несколько снижает высоту барьера для $X$-электронов. Практическая реализация ненапряженных гетероструктурных КЯ $\mathrm{In}_{x} \mathrm{Al}_{1-x} \mathrm{As} / \mathrm{In}_{x} \mathrm{Ga}_{1-x} \mathrm{As}$ с высотой барьера КЯ $\Delta E_{c} \approx 0.4-0.5$ эВ возможна на подложках InP, либо при помощи метаморфной технологии (metamorphic high-electron-mobility transistor, MHEMT) на подложках GaAs. Однако недостатком MHEMTструктур с высоким содержанием InAs является уменьшение запрещенной зоны $E_{g}$ в узкозонной КЯ, что может приводить к возникновению эффектов пробоя $[13,14]$ и негативно сказываться на мощностных характеристиках транзисторов [15].

Увеличить эффективную глубину квантовой ямы при сохранении исходных параметров толщины и состава $\mathrm{In}_{y} \mathrm{Ga}_{1-y} \mathrm{As}$ предлагается за счет изменения 
высоты барьеров, при переходе от псевдоморфной $\mathrm{Al}_{x} \mathrm{Ga}_{1-x} \mathrm{As} / \mathrm{In}_{y} \mathrm{Ga}_{1-y} \mathrm{As} / \mathrm{GaAs}$ к метаморфной гетероструктуре $\operatorname{In}_{x} \mathrm{Al}_{1-x} \mathrm{As} / \mathrm{In}_{y} \mathrm{Ga}_{1-y} \mathrm{As} / \mathrm{In}_{x} \mathrm{Al}_{1-x} \mathrm{As}$, при сохранении аналогичного РНЕМТ-структуре содержания индия $x \approx 20 \%$. Принципиальным отличием данной метаморфной структуры от псевдоморфной с аналогичным составом ямы является то, что барьером в ней является $\mathrm{In}_{0.2} \mathrm{Al}_{0.8} \mathrm{As}$, запрещенная зона которого больше, чем в $\mathrm{Al}_{0.25} \mathrm{Ga}_{0.75} \mathrm{As}$, вследствие чего яма $\mathrm{In}_{0.2} \mathrm{Ga}_{0.8} \mathrm{As}$, окруженная барьерами из $\mathrm{In}_{0.2} \mathrm{Al}_{0.8} \mathrm{As}$, будет глубже. Однако слой $\mathrm{In}_{0.2} \mathrm{Al}_{0.8} \mathrm{As}$ с мольной долей InAs 0.2 является непрямозонным. Энергия дна зоны проводимости для $X$-долины в нем меньше, чем для Г-долины, из-за чего эффективная высота стен барьера будет почти в 2 раза меньше. Разрыв между барьером и ямой только для Г-долины составляет $\sim 0.70$ эВ, в то время как с учетом $X$-долины он будет всего $\sim 0.46$ эВ. Таким образом, эффективная высота барьера в метаморфной структуре будет в итоге на 0.11 эВ больше, чем в псевдоморфной. Однако туннелирование электронов в барьер $\operatorname{In}_{0.2} \mathrm{Al}_{0.8} \mathrm{As}$ будет значительно меньше, чем для аналогичного прямозонного барьера, поскольку является междолинным переходом.

Помимо этого в РНЕМТ-гетероструктуре слои квантовой ямы и барьера являются решеточно-несогласованными, поэтому кристаллическая решетка узкозонного слоя $\mathrm{In}_{0.2} \mathrm{Ga}_{0.8} \mathrm{As}$ напряжена. В метаморфной же структуре разница в параметрах решетки ликвидируется при помощи буферного слоя, поэтому барьер и яма являются решеточно-согласованными и лишены недостатков РНЕМТ.

Для ряда практических применений, например, в СВЧ-транзисторах и схемах средней мощности в частотных $X$ - и $K$-диапазонах, увеличение мольной доли InAs в КЯ нежелательно вследствие снижения энергии запрещенной зоны, из-за чего ограничивается пробойное напряжение транзистора и его мощность. Для таких приложений выгодным является сохранение состава канала $\operatorname{In}_{x} \mathrm{Ga}_{1-x} \mathrm{As}$ на уровне $x \approx 0.20-0.25$ одновременно с увеличением барьера КЯ, в связи с чем КЯ МНЕМТ-структур с $x \approx 25 \%$ могут представлять практический интерес. Кроме того, рассогласование параметров решетки относительно подложки GaAs в таких структурах меньше, поэтому метаморфный согласующий буфер может быть более тонким, что экономит время эпитаксиального роста таких структур, а значит, и их стоимость.

Известно только одно исследование МНЕМТ-КЯ с небольшим содержанием In, $x=0.27$. В работе [16] была получена концентрация электронов $4 \cdot 10^{12} \mathrm{~cm}^{-2}$ при подвижности $8500 \mathrm{~cm}^{2} / \mathrm{B} \cdot \mathrm{c}$, что заметно превосходит параметры РНЕМТ-КЯ. Однако структура КЯ сильно отличалась от диктуемой современными требованиями. КЯ имела очень большую ширину слоя $\mathrm{In}_{x} \mathrm{Ga}_{1-x} \mathrm{As}, \sim 300$ нм, поэтому в структуре фактически формировалась квазитреугольная самосогласованная КЯ вблизи гетероперехода $\operatorname{In}_{x} \mathrm{Al}_{1-x} \mathrm{As} / \mathrm{In}_{x} \mathrm{Ga}_{1-x} \mathrm{As}$. Также исследованная структура имела объемное легирование и большую глубину залегания КЯ.

\section{2. Эксперимент}

Для исследования особенностей электронного транспорта была выращена серия образцов, состоящая из опорной РНЕМТ-гетероструктуры с односторонним $\delta$-легированием кремнием (384) и двух МНЕМТ-гетероструктур (422) и (433), имеющих ступенчатый и линейный тип метаморфного буфера соответственно. Структуры имели одинаковую концентрацию доноров кремния в $\delta$-слое. Все образцы были выращены на подложках полуизолирующего GaAs (100) методом молекулярнолучевой эпитаксии в Наноцентре НИЯУ МИФИ на установке Riber Compact 21-T. Для улучшения структурного качества буфера вблизи подложки выращивалась сверхрешетка (CP/SL) AlGaAs/GaAs. Слоевая конструкция активной области структур совпадала, образцы различались материалом барьерных и спейсерных слоев. Все образцы имели одностороннее $\delta$-легирование кремнием через спейсер $\mathrm{Al}_{0.25} \mathrm{Ga}_{0.75} \mathrm{As}$ в случае PHЕМТ и $\mathrm{In}_{0.2} \mathrm{Al}_{0.8} \mathrm{As}$ в случае MHEMT, который также является барьером для квантовой ямы $\mathrm{In}_{0.22} \mathrm{Ga}_{0.78} \mathrm{As}$.

Структура исследуемых образцов схематически показана на рис. 1. Концентрация доноров кремния в легирующем слое составляла $N_{2 \mathrm{D}}=2.5 \cdot 10^{12} \mathrm{~cm}^{-2}$ в каждом из образцов и калибровалась по измерению концентрации электронов в объемно легированном $\mathrm{GaAs}(\mathrm{Si})$.

В образце 422 в качестве метаморфного буфера (ММБ) (рис 1,b) был использован ступенчатый буфер, состоящий из двух слоев: InAlGaAs (1-я ступень) с содержанием In $x=0.1$ и толщиной $\sim 310$ нм, InAlAs (2-я ступень) с содержанием In $x=0.18$ и толщиной 155 нм. Метаморфный буфер образца 433 состоял из слоя с линейным изменением $x 0.05 \rightarrow 0.25$ в пределах толщины 546 нм и инверсной ступени толщиной 50 нм, в которой содержание индия $x$ изменяется также линейно $0.25 \rightarrow 0.22$. Для сглаживания поверхности в образце 422 со ступенчатым метаморфным буфером после каждой ступени использовались сверхрешетки InAlAs/InGaAs, препятствующие прорастанию дислокаций в область канала, а в образце 433 с линейным ММБ - инверсная ступень InAlAs для снижения механических напряжений, вызванных перепадом состава.

Температура роста слоя $\mathrm{In}_{0.22} \mathrm{Ga}_{0.78} \mathrm{As}$ составляла $490^{\circ} \mathrm{C}$, остальных слоев $\sim 610^{\circ} \mathrm{C}$ в РНЕМТ-гетероструктуре и $400^{\circ} \mathrm{C}$ в образцах 422 и 433, оптимальных с точки зрения предотвращения сегрегации индия в вышележащие слои. Эквивалентное давление потока мышьяка $\mathrm{As}_{4}$ при росте слоев и формировании $\delta$-слоя кремния составляло $2 \cdot 10^{-5}$ Торр. Для проведения измерений на выращенных структурах формировались мезы типа „мост Холла“ с помощью фотолитографии и жидкостного травления. Для получения надежных 


\begin{tabular}{|c|c|c|c|}
\hline$i$-GaAs (cap) & $8 \mathrm{~nm}$ & $i$-GaAs (cap) & $8 \mathrm{~nm}$ \\
\hline $\mathrm{Al}_{x} \mathrm{Ga}_{1-x} \mathrm{As}$ (barrier) & $26 \mathrm{~nm}$ & $\mathrm{Al}_{x} \mathrm{Ga}_{1-x} \mathrm{As}$ (barrier) & $26 \mathrm{~nm}$ \\
\hline$\delta$-Si $\left(N_{D}\right)$ & $2.5 \cdot 10^{12} \mathrm{~cm}^{-2}$ & $\delta-\operatorname{Si}\left(N_{D}\right)$ & $2.5 \cdot 10^{12} \mathrm{~cm}^{-2}$ \\
\hline & & $\mathrm{Al}_{x} \mathrm{Ga}_{1-x} \mathrm{As}$ (spacer) & $5 \mathrm{~nm}$ \\
\hline $\mathrm{Al}_{x} \mathrm{Od}_{1-x} \mathrm{As}$ (spacer) & กा & $\mathrm{In}_{y(z)} \mathrm{Ga}_{1-v(z)} \mathrm{As}(\mathrm{QW})$ & $10.5 \mathrm{~nm}$ \\
\hline $\mathrm{In}_{y(z)} \mathrm{Ga}_{1-y(z)} \mathrm{As}(\mathrm{QW})$ & $10.5 \mathrm{~nm}$ & \multirow[b]{2}{*}{ MMB } & \multirow[b]{2}{*}{$500-600 \mathrm{~nm}$} \\
\hline GaAs (buffer) & $0.35 \mathrm{~nm}$ & & \\
\hline $\mathrm{Al}_{x} \mathrm{Ga}_{1-x} \mathrm{SL} / \mathrm{As} / \mathrm{GaAs}$ & $1 \mathrm{~nm} / 1 \mathrm{~nm}$ & $\stackrel{\mathrm{SL} 1}{\mathrm{Al}_{x} \mathrm{Ga}_{1-x} \mathrm{As} / \mathrm{GaAs}}$ & $1 \mathrm{~nm} / 1 \mathrm{~nm}$ \\
\hline (100) GaAs substrate & & (100) GaAs substrate & \\
\hline
\end{tabular}

Рис. 1. Слоевая схема образцов: $a-$ псевдоморфный, $b-$ метаморфный.

омических контактов использовался сплав AuGeNi с последующим быстрым термическим отжигом при $380^{\circ} \mathrm{C}$ в течение 3 мин, после чего контролировалась линейность вольт-амперных характеристик контактов. Измерения подвижности и концентрации электронов проводились на установке CryoFree404 в темноте в магнитных полях до 6 Тл в интервале температур $2.1-300 \mathrm{~K}$.

Исследование морфологии поверхности при помощи атомно-силовой микроскопии показало, что среднеквадратичная шероховатость для метаморфного образца 422 составила $\mathrm{RMS}=2.9$ нм, что хуже, чем для образца 433 $\mathrm{c} \mathrm{RMS}=1.8$ нм. Это объясняется большей релаксацией кристаллической решетки в буферном слое в случае метаморфных ступеней (образец 422) по сравнению с плавным линейным изменением состава в образце 433 и использованием инверсной ступени, позволяющей уменьшить пластическую деформацию в активных слоях гетероструктуры. При этом значения RMS для опорного образца РНЕМТ 384 составили 0.2 нм.

\section{3. Моделирование}

Использование AlInAs вместо AlGaAs в качестве барьера в МНЕМТ-гетероструктуре приводит к увеличению эффективной высоты барьеров КЯ, а также поверхностного барьера Шоттки и к увеличению эффективной глубины квантовой ямы. Вследствие этого в МНЕМТ-структуре КЯ двумерный газ сильнее локализован в узкозонном слое КЯ, снижается проникновение электронов в спейсер, а значит, должно уменьшаться рассеяние электронов на ионизованных донорах кремния и на шероховатостях гетерограниц КЯ.

Для подтверждения этой гипотезы при помощи решения самосогласованной системы уравнений Шредингера и Пуассона были построены зонные диаграммы (рис. 2, z - координата в направлении роста слоев) для опорной РНЕМТ-гетероструктуры $\mathrm{Al}_{0.22} \mathrm{Ga}_{0.78} \mathrm{As} / \mathrm{In}_{0.22} \mathrm{Ga}_{0.78} \mathrm{As}$ и предлагаемой МНЕМТгетероструктуры $\operatorname{In}_{0.22} \mathrm{Al}_{0.78} \mathrm{As} / \mathrm{In}_{0.22} \mathrm{Ga}_{0.78} \mathrm{As}$ при одинаковом легировании $N_{D}=2.5 \cdot 10^{12} \mathrm{~cm}^{-2}$ и температуре 300 K. Во-первых, видно, что из-за увеличения эффективной глубины КЯ значительно улучшается локализация Г-электронов в яме. Во-вторых, увеличивается зазор (на $\sim 26$ мэВ) между второй и первой подзонами. При этом расчетное значение разрывов зон для Г-долин $\Delta E_{g}$, характеризующее глубину КЯ, для МНЕМТ в 2 раза выше, чем для РНЕМТ, и составляет $\sim 0.7$ эВ. В результате этого в квантовой яме при концентрации электронов $2.0 \cdot 10^{12} \mathrm{~cm}^{-2}$ и температуре $300 \mathrm{~K}$ заполненными являются только первые две подзоны размерного квантования. При этом волновые функции электронов этих подзон, $\psi_{\Gamma 1}$ и $\psi_{\Gamma 2}$, локализованы в яме и практически не проникают в барьер. Ближайшей к $E_{2}$ по энергии подзоной в МНЕМТ-КЯ является $X$-зона $E_{3}$, ассоциированная с $V$-образной ямой, расположенной в барьере $\mathrm{In}_{0.2} \mathrm{Al}_{0.8} \mathrm{As}$. Волновая функция $\psi_{X 1}$ этой подзоны локализована строго в окрестности легирующего $\delta$-слоя. Таким образом, все состояния остаются негибридизован- 

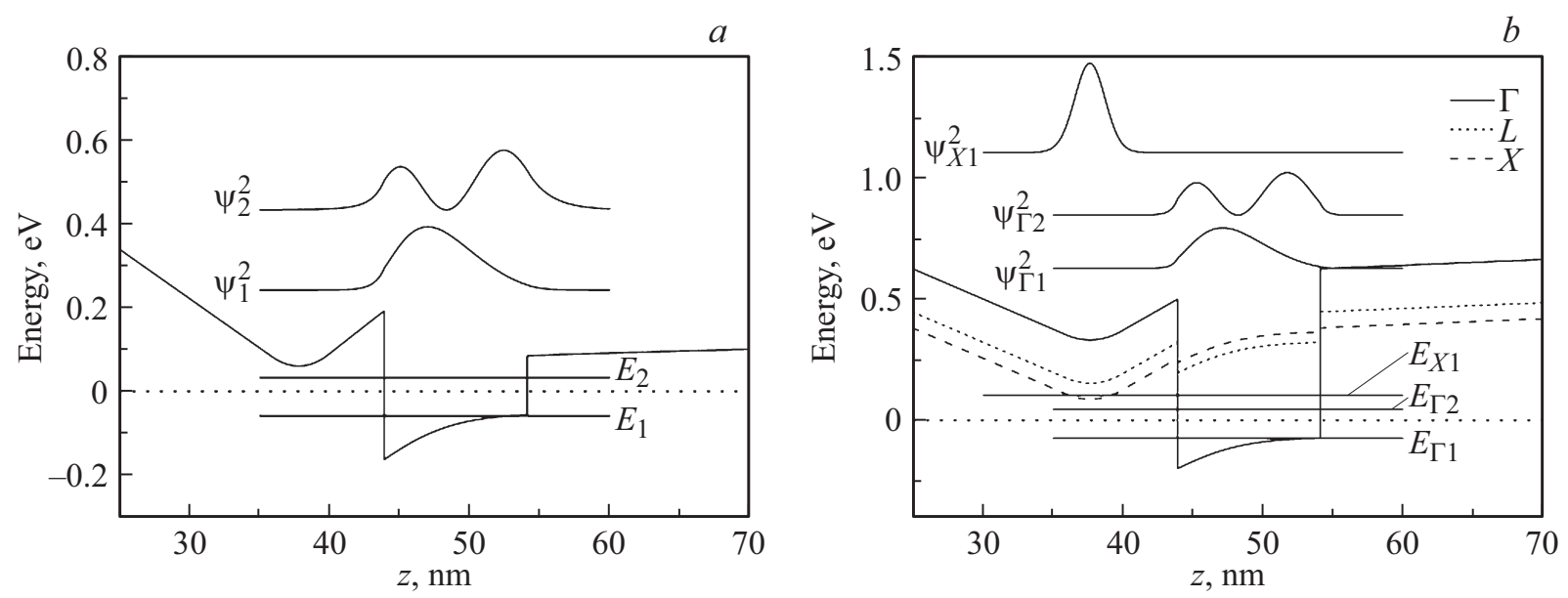

Рис. 2. Сравнение зонных диаграмм PHЕМТ- $(a)$ и MHEMT- $(b)$ гетероструктуры .
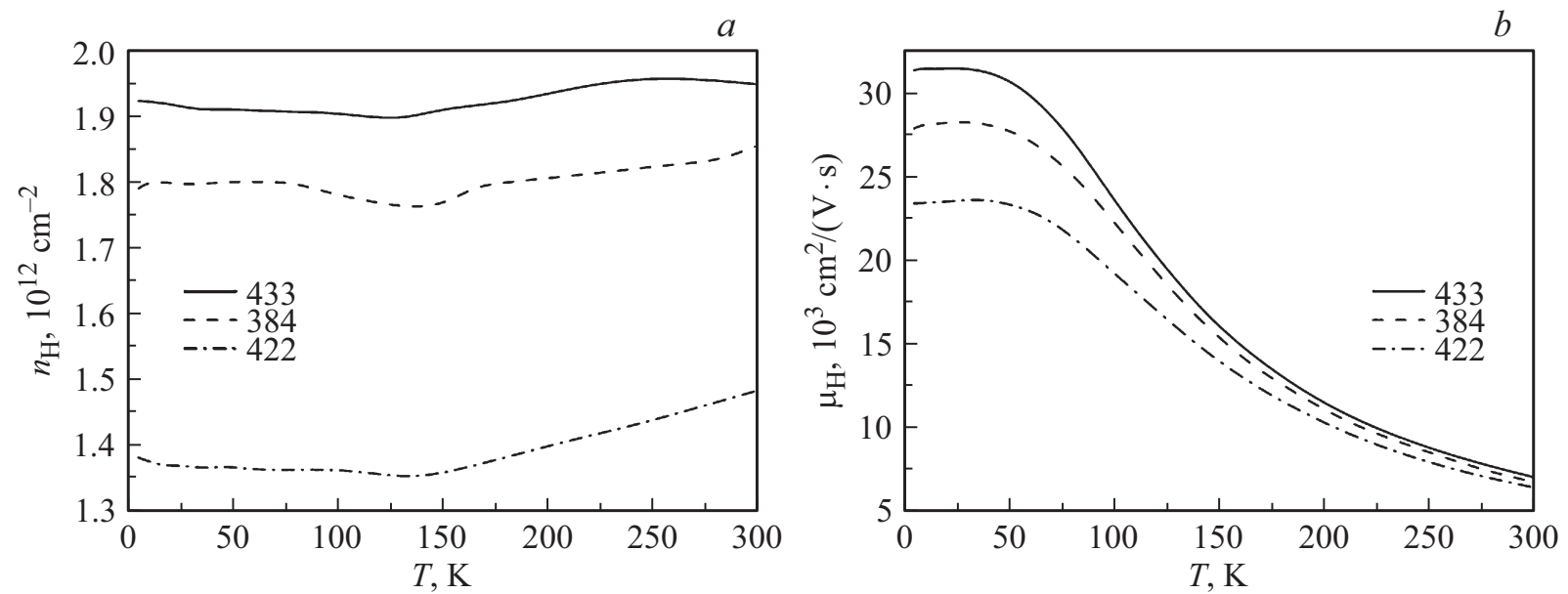

Pис. 3. Температурные зависимости холловских концентрации $(a)$ и подвижности $(b)$ электронов в исследуемых образцах.

ными и локализованными в соответствующих им ямах. Поскольку для $X$-подзоны $E_{3}$ отсутствует близкая ей по энергии подзона Г-электронов, $Г-X$-туннелирование в барьер должно быть заметно подавлено.

Таким образом, использование МНЕМТ-гетероструктур с тем же составом канала, но с более широкозонным барьером InAlAs, приводит к увеличению глубины КЯ по сравнению с РНЕМТ-гетероструктурой и должно увеличить электронную подвижность за счет снижения рассеяния на шероховатостях гетерограниц и уменьшения рассеяния на ионизованной примеси доноров $\mathrm{Si}$ вследствие снижения туннелирования высокоподвижных электронов Г-зоны из области канала в спейсер.

\section{Результаты измерений и обсуждение}

На меза-структурах исследовались температурные зависимости удельного сопротивления, холловской концентрации электронов $n_{\mathrm{H}}$ (рис. $\left.3, a\right)$ и их холловской подвижности $\mu_{\mathrm{H}}$ (рис. $\left.3, b\right)$ в интервале температур
$T=4-300 \mathrm{~K}$. Во всем диапазоне измерений более высокие значения холловских подвижности и концентрации электронов наблюдаются в образце 433, а минимальные в образце 422. Это можно связать с тем, что использование ступенчатого ММБ приводит к формированию более высокой плотности прорастающих в активные слои дислокаций, которые выступают как глубокие центры захвата носителей заряда. Вид зависимостей $\mu_{\mathrm{H}}(T)$ одинаков для всех образцов и типичен для НЕМТ-структур с высоким структурным совершенством. Резкое уменьшение $\mu_{\mathrm{H}}$ при $T>80 \mathrm{~K}$ связано с увеличением рассеяния на оптических фононах. Однако зависимости $n_{\mathrm{H}}(T)$ различаются. В псевдоморфной КЯ (образец 384 ) концентрация электронов изменяется во всем диапазоне в пределах 5\%, в то время как в образце 422 концентрация увеличивается на 7\% при увеличении температуры от 2.1 до $300 \mathrm{~K}$. Кроме того, $n_{\mathrm{H}}$ более чувствительна к освещению в этом образце. Данные эффекты можно объяснить дополнительной термо- и фотоионизацией электронов с глубоких уровней структурных дефектов (дислокаций). Напротив, в образце 433 с линейной кон- 
Квантовые и транспортные времена релаксации импульса и значения эффективных масс электронов в экспериментальных образцах

\begin{tabular}{c|l|l|l}
\hline Образец & $\tau_{t}$, пс & $\tau_{q}$, пс & $m^{*} / m_{0}$ \\
\hline 384 & 1.14 & 0.164 & 0.070 \\
422 & 0.872 & 0.0695 & 0.066 \\
433 & 1.19 & 0.0647 & 0.067
\end{tabular}

струкцией ММБ температурное изменение $n_{\mathrm{H}}$ оказывается несколько ниже, чем в РНЕМТ, и составляет 3\%, что указывает на сниженную плотность структурных дефектов.

Для исследования квантового магнетотранспорта измерены осцилляции Шубникова-де Гааза (ШдГ). Фурьеанализ осцилляций ШдГ показал, что при гелиевых температурах $(T \approx 4 \mathrm{~K})$ во всех образцах заполнена только одна подзона размерного квантования. Эффективную массу носителей заряда вычислили исходя из температурной зависимости амплитуды осцилляций ШдГ по формуле [17,18]

$$
m^{*}=\hbar e B \operatorname{arch}\left[\Delta R\left(T_{2}, B\right) / \Delta R\left(T_{1}, B\right)\right] /\left(2 \pi^{2} k T_{2}\right),
$$

где $T_{1}=2 T_{2}, \Delta R=R_{x x}-R_{0}, R_{x x}-$ амплитуда осцилляций сопротивления, $R_{0}-$ сопротивление в отсутствие магнитного поля $B$. В данной работе проводились измерения при наборе кратных температур 2.1, 4.2 и $8.4 \mathrm{~K}$ для увеличения точности определения эффективной массы.

Квантовое время релаксации импульса рассчитано из пиков осцилляций ШдГ по методу Дингла. Амплитудная зависимость осцилляций описывается соотношением [19]

$$
\Delta R \operatorname{sh}\left(A_{T}\right) / 4 R_{0} A_{T}=\exp \left(-\pi / \omega_{c} \tau_{q}\right),
$$

где $A_{T}=2 \pi^{2} k T / \hbar \omega_{c}, \omega_{c}=e B / m^{*}$. При построении графика Дингла - зависимости $\ln \left[\Delta R \operatorname{sh}\left(A_{T}\right) / 4 R_{0} A_{T}\right]$ от обратного магнитного поля - точки должны лечь на прямую линию, наклон которой равен $\pi m^{*} / e \tau_{q}$. Зная значение эффективной массы $m^{*}$, можно из угла наклона экстраполированной по экспериментальным данным прямой рассчитать квантовое время рассеяния $\tau_{q}$.

Измеренные параметры приведены в таблице для всех образцов. Видно, что эффективная масса электронов в МНЕМТ-структуре несколько меньше, чем в PHEMT-структуре. Это можно связать с отсутствием механического напряжения кристаллической решетки слоя InGaAs в MHEMT-КЯ, поскольку содержание InAs в канале и в барьере КЯ совпадает. Значения транспортного времени релаксации $\tau_{t}$ в образцах 384 и 433 сопоставимы, в то время как в образце $422 \tau_{t}$ меньше. Поскольку значения концентрации электронов и их эффективной массы наименьшие в этом образце, можно сделать вывод, что уменьшение подвижности в 422 по сравнению с 384 вызвано в первую очередь высокой дефектностью структуры, сформированной на ступенчатом метаморфном буфере. Таким образом, в метаморфных структурах даже с относительно небольшим содержанием индия использование линейного метаморфного буфера является более оптимальным.

Особенностью МНЕМТ-КЯ являются более низкие значения квантового времени рассеяния электронов (различие более чем в 2 раза), чем в РНЕМТ-КЯ. Однако различие $\tau_{q}$ для двух МНЕМТ-структур оказывается небольшим. Совместный анализ значений $\tau_{t}$ и $\tau_{q}$ говорит о том, что рассеяние на большие углы изменяется не столь значительно в МНЕМТ по сравнению с РНЕМТ, в то время как рассеяние на малые углы заметно возрастает в МНЕМТ. Таким образом, преобладающим механизмом рассеяния остается рассеяние на удаленной ионизованной примеси [20].

\section{4. Заключение}

Проведено сравнение односторонне $\delta$-легированных метаморфных и псевдоморфных квантовых ям с одинаковым каналом $\mathrm{In}_{0.2} \mathrm{Ga}_{0.8} \mathrm{As}$, различающихся материалами ограничивающих канал барьеров $\left(\mathrm{Al}_{0.25} \mathrm{Ga}_{0.75} \mathrm{As}\right.$ и $\mathrm{Al}_{0.8} \mathrm{In}_{0.2} \mathrm{As}$ ) и составом. Было выполнено моделирование зонных диаграмм изучаемых структур, а также проведены исследования электронного транспорта в слабом и сильном магнитных полях в широком интервале температур. Морфология поверхности была проанализирована при помощи атомно-силовой микроскопии. Показано, что транспортная подвижность электронов оказывается выше в метаморфной КЯ по сравнению с псевдоморфно-напряженной, несмотря на то что квантовая подвижность электронов выше в РНЕМТ-структуре. Наиболее оптимальным с точки зрения электронного транспорта является использование решеточносогласованных гетероструктур InAlAs/InGaAs/InAlAs c линейным метаморфным буфером.

Исследование проводилось в рамках научно-исследовательской работы по выполнению государственного задания (№ 8.3887.2017/ПЧ).

\section{Список литературы}

[1] S. Chaturvedi, S.L. Badnikar, A.A. Naik. 2017 IEEE MTT-S Int. Microwave and RF Conf. (Ahmedabad, India, 2017).

[2] K. Wang, Y. Yan, X. Liang. 2018 IEEE MTT-S Int. Wireless Symp. (Chengdu, China, 2018).

[3] T. Paul, M. Harinath, S.K. Garg. 2017 IEEE MTT-S Int. Microwave and RF Conf. (Ahmedabad, India, 2017).

[4] M. Kasu, S. Fujita, A. Sasaki. J. Appl. Phys., 66, 3042 (1989).

[5] N. Chand, T. Henderson, J. Klem, W. Ted Masselink, R. Fischer, Y.-C. Chang, H. Morkoc. Phys. Rev. B, 30, 4481 (1984).

[6] M.E. Rudinsky, S.Yu. Karpov, H. Lipsanen, A.E. Romanov. Mater. Phys. Mechanics, 24, 278 (2015). 
[7] H. Sari, H.H. Wieder. J. Appl. Phys., 85, 3380 (1999).

[8] P.M. Mooney. J. Appl. Phys., 67, R1 (1990).

[9] A. Malinin, H. Tomozawa, T. Hashizume, H. Hasegawa. Jpn. J. Appl. Phys., 34, 1138 (1995).

[10] S. Adachi. Physical properties of III-V semiconductor compounds: InP, InAs, GaAs, GaP, InGaAs, and InGaAsP (Chichester, UK, John Wiley \& Sons, 1992).

[11] I. Vurgaftman, J.R. Meyer, L.R. Ram-Mohan. J. Appl. Phys., 89, 5815 (2001).

[12] И.С. Васильевский, Г.Б. Галиев, Е.А. Климов, В.Г. Мокеров, С.С. Широков, Р.М. Имамов, И.А. Субботин. ФТП, 42, 1102 (2008).

[13] R.T. Webster, S. Wu, A.F.M. Anwar. IEEE Electron Dev. Lett., 21, 193 (2000)

[14] G. Berthold, E. Zanoni, C. Canali, M. Pavesi, M. Pecchini, M. Manfredi, S.R. Bahl, J.A. del Alamo. IEEE Trans. Electron Dev., 42, 752 (1995).

[15] K. Kalna, A. Asenov. Solid-State Electron., 48, 1223 (2004).

[16] P. Win, Y. Cordier, Y. Druelle, C. Bouillet, J. Favre, A. Cappy. Microelectronic Engin., 19, 317 (1992).

[17] В.А. Кульбачинский, Л.Н. Овешников, Р.А. Лунин, Н.А. Юзеева, Г.Б. Галиев, Е.А. Климов, П.П. Мальцев. ФТП, 49, 204 (2015).

[18] N.A. Yuzeeva, A.V. Sorokoumova, R.A. Lunin, L.N. Oveshnikov, G.B. Galiev, E.A. Klimov, D.V. Lavruchin, V.A. Kulbachinskii. J. Low Temp. Phys., 185, 701 (2016).

[19] E. Diez, Y.P. Chen, S. Avesque, M. Hilke, E. Peled, D. Shahar, J.M. Cerveró, D.L. Sivco, A.Y. Cho. Appl. Phys. Lett., 88, 052107 (2006).

[20] D.Yu. Protasov, K.S. Zhuravlev. Solid-State Electron., 129, 66 (2017).

Редактор Л.В. Шаронова

\section{Electron quantum transport \\ in pseudomorphic and metamorphic quantum wells based on $\ln _{0.2} \mathbf{G a}_{0.8}$ As.}

A.N. Vinichenko, D.A. Safonov, N.I. Kargin, I.S. Vasil'evskii

National Research Nuclear University „MEPhl“, 115409 Moscow, Russia

Abstract For the first time metamorphic deep quantum wells $\mathrm{In}_{0.2} \mathrm{Ga}_{0.8} \mathrm{As} / \mathrm{In}_{0.2} \mathrm{Al}_{0.8} \mathrm{As}(0.7 \mathrm{eV}$ for $\Gamma$-electrons $)$ for MHEMT with various metamorphic buffer design were implemented. A comparative analysis of electron transport properties of MHEMT and PHEMT (pseudomorphic) structures is presented for the same doping concentration. MHEMT structure with linear buffer showed an increase of both electron mobility and concentration in the temperature range $4-300 \mathrm{~K}$ compared to PHEMT due to quantum well depth increase. Low-temperature magnetotransport measurements revealed reduction of quantum relaxation time in MHEMT compared to PHEMT due to strengthening of small angle scattering mechanisms such as structural defects and inhomogeneities scattering, while the dominant scattering mechanism is still due to remote ionized impurity. 